\title{
Varones peruanos en Argentina y trayectorias laborales en costura. Masculinidades, roles de género y organización del trabajo en contextos migratorios $^{1}$
}

\author{
Maria José Magliano \\ $\mathrm{CONICET}^{3}$ \\ Universidad Nacional de Córdoba, Córdoba, Argentina ${ }^{4}$ \\ majomagliano@gmail.com \\ Recibido: 10 de noviembre de 2014 \\ Aceptado: 11 de mayo de 2015 \\ Disponible en linea: 30 de noviembre de 2015
}

\begin{abstract}
Artículo de reflexión que presenta los resultados de un trabajo de campo realizado durante el periodo 2012-2014 en la ciudad de Córdoba (Argentina), como parte del proyecto de investigación "Estrategias y trayectorias migratorias de mujeres y varones bolivianos y peruanos en Córdoba: implicaciones de género, etnicidad y clase social", financiado por el Consejo Nacional de Investigaciones Científicas y Técnicas (CONICET) en el marco de la carrera de Investigador Científico.

2 Doctora en Historia (Universidad Nacional de Córdoba). Coordinadora del Programa de Investigación "Multiculturalismo, migraciones y desigualdad en América Latina" (CIECS-CONICET/ UNC).

3 Investigadora adjunta del Consejo Nacional de Investigaciones Científicas y Técnicas (CONICET), con lugar de trabajo en el Centro de Investigaciones y Estudios sobre Cultura y Sociedad (CIECSCONICET y UNC), Córdoba.

4 Profesora de la Facultad de Filosofia y Humanidades (UNC).
\end{abstract}




\title{
Varones peruanos en Argentina y trayectorias laborales en costura. Masculinidades, roles de género y organización del trabajo en contextos migratorios
}

\begin{abstract}
Resumen
Con base en los hallazgos de una investigación cualitativa con mujeres y varones peruanos en la ciudad de Córdoba, Argentina, este artículo indaga sobre la articulación entre las masculinidades heterosexuales migrantes y el mundo del trabajo, en particular la costura, analizando las implicancias de ciertas trayectorias laborales en las marcas que configuran las feminidades y masculinidades en contextos migratorios y de exclusión social. A partir del estudio de caso de una familia de migrantes costureros, el artículo reflexiona acerca de las experiencias laborales en relación con las prácticas y sentidos de la identidad masculina y con las resistencias que despliegan los varones frente a la feminización de su actividad. Para ello, recupera trayectorias laborales en origen (Perú) y destino (Argentina), reconociendo la existencia de mercados de trabajo que, en ciertas ocupaciones, se encuentran conectados a partir de la existencia de redes laborales étnico-nacionales constituidas por un importante conjunto de personas que primero fueron migrantes internos y luego internacionales.

Palabras claves: migraciones; costura; masculinidades; roles de género; trayectorias laborales

\section{Male Peruvians in Argentina and career paths in sewing. Masculinities, gender roles and work organization in migration contexts}

\begin{abstract}
Based on the findings of a qualitative research with Peruvian women and men in the city of Cordoba, Argentina, this article explores the links between heterosexual male migrants and the world of work, particularly sewing, analyzing the implications of certain work paths on the marks that configure femininity and masculinity in immigration and social exclusion contexts. From the case study of a migrant family of tailors, the article reflects on work experiences in relation to the practice and meaning of masculine identity and the resistance men deployed against the feminization of their activity. To this end, it goes back to the career paths in the origin (Peru) and the destination (Argentina), recognizing the existence of labor markets that in certain occupations are connected due to the existence of ethnic and national labor networks constituted by an important set of people who were first internal and then international migrants.
\end{abstract}

Keywords: migration; sewing; masculinities; gender roles; career paths

\section{Varões peruanos na Argentina e trajetórias laborais em costura. Masculinidades, papeis de gênero e organização do trabalho em contextos migratórios}

\section{Resumo}

Baseados nos achados de pesquisa qualitativa com mulheres e varões peruanos na cidade de Córdoba, Argentina, este artigo investiga sobre a articulação entre as masculinidades heterossexuais migrantes e o mundo do trabalho, em particular da costura, analisando as implicações de certas trajetórias laborais nos traços que configuram feminidades e masculinidades em contextos migratórios e de exclusão social. A partir do estudo de caso de uma família de migrantes costureiros, o artigo reflete acerca das experiências laborais no que diz respeito das práticas e sentidos da identidade masculina e das resistências desdobradas pelos varões frente à feminização da sua atividade. Para isso, recupera trajetórias laborais na origem (Peru) e destino (Argentina), reconhecendo que há mercados de trabalho que, em certas ocupações, encontram-se vinculados a partir da existência de redes laborais étnico-nacionais constituídas por um conjunto grande de pessoas que primeiro foram migrantes internos e após internacionais.

Palavras-chave: migrações; costura; masculinidades; papeis de gênero; trajetórias laborais 


\section{Introducción}

Con base en los hallazgos de una investigación propia de carácter cualitativo con mujeres y varones peruanos en la ciudad de Córdoba, Argentina, este artículo indaga acerca de la articulación entre las masculinidades heterosexuales migrantes y el mundo del trabajo, en especial el universo de la costura y los talleres textiles, analizando las implicancias de ciertas trayectorias laborales en las marcas que configuran las feminidades y masculinidades en contextos migratorios y de exclusión social. A partir del estudio de caso de una familia de migrantes costureros, reconstruye las experiencias laborales en el país de origen (Perú) y destino (Argentina), reconociendo la existencia de mercados de trabajo que, en ciertas ocupaciones, se encuentran conectados a partir de la existencia de redes laborales étnico-nacionales constituidas por un importante número de personas que primero fueron migrantes internos y luego internacionales.

La migración peruana hacia Argentina, en general, y en Córdoba, en particular, está relacionada con la búsqueda de mejores oportunidades socio-económicas. Se trata de un flujo que se magnificó en los años noventa, joven y con una alta concentración en zonas urbanas, sobre todo Buenos Aires, Córdoba y Mendoza (Cerrutti, 2005; Falcón Aybar y Bologna, 2013; Rosas, 2010). A diferencia de la década del noventa, donde la migración peruana se distinguía por su feminización -siendo la mujer pionera del proyecto migratorio-, en los últimos años se destaca una mayor diversificación de las dinámicas migratorias. En tal sentido, la migración de mujeres solas se combina con procesos migratorios que involucran a la familia en su conjunto.

En la ciudad de Córdoba, un significativo porcentaje de los migrantes peruanos, tanto varones como mujeres, se dedica a la costura, ocupación que se organiza principalmente en torno a redes laborales con alta presencia masculina. En la esfera de la industria textil, los y las migrantes se concentran en el último eslabón de la cadena productiva: la confección de prendas. Este eslabón se encuentra generalmente tercerizado fuera de las empresas a través de la contratación 
de talleristas, quienes muchas veces subcontratan a otros talleres o trabajadores domiciliarios para la realización del trabajo.

En los últimos años, las trayectorias en costura por parte de los y las migrantes en Argentina han cobrado mayor interés dentro del ámbito académico y político. Estos trabajos se focalizan, especialmente, en los modos de inserción en la costura (Bastia, 2007), en las condiciones de explotación y exclusión que los y las trabajadoras migrantes enfrentan (Barattini, 2010; Benencia, 2009; Defensoría del Pueblo de la Ciudad de Buenos Aires, 2011; Foro Ciudadano, 2009) $)^{5}$ y en los problemas de salud derivados de las formas en que se desarrolla esta actividad en las ciudades (Goldberg, 2013). Un aspecto poco estudiado gira en torno a las implicancias en los roles y relaciones de género que suponen las inserciones laborales de varones migrantes en empleos no convencionales, en especial aquellos asignados tradicionalmente a las mujeres, como la costura. Indagar sobre este aspecto permitirá poner en discusión la idea de lo masculino y lo femenino como modalidades excluyentes y analizar los procesos de masculinización y feminización -y sus resistencias- en espacios laborales y familiares.

En América Latina los varones migrantes y sus trayectorias laborales han recibido escasa atención por parte de los estudios sobre género y migración (Herrera, 2012; Hondagneu-Sotelo, Estrada, y Ramírez, 2011; Rosas, 2008; 2013). Aun cuando el trabajo productivo resulta un espacio clave para los varones, en tanto eje articulador de la identidad masculina y de la vida en sociedad (Fuller, 2005; Rosas, 2013; Salguero Velázquez, 2007; Vivero Vigoya, 2002), poco se ha investigado sobre los varones -en este caso migrantes- en inserciones laborales concebidas como 'femeninas'. Así pues, este artículo busca contribuir a la discusión sobre migraciones y trabajo a partir de una reflexión crítica acerca de las experiencias laborales y cotidianas de varones migrantes que trabajan en costura, en relación con las prácticas y sentidos de su

\footnotetext{
Si bien la mayoría de los y las migrantes que se desempeñan en la costura se encuentran en situaciones de precariedad, informalidad y explotación (largas horas de trabajo, malas condiciones espaciales y laborales, etc.), no se contemplan en este articulo aquellas trayectorias laborales que se encuadran dentro del denominado 'trabajo esclavo', esto es, el ejercicio sobre los individuos de atributos de derecho de propiedad, el tratamiento como una cosa sometida a la voluntad y a la acción de otras personas (Barattini, 2010, p. 464).
} 
identidad masculina y con las resistencias que despliegan frente a la feminización de su actividad.

\section{Punteos metodológicos y recorridos teóricos}

En términos metodológicos, este artículo se desprende de un trabajo de campo realizado entre 2012 y 2014 en un barrio ubicado sobre terrenos fiscales del Estado nacional en la periferia este de la ciudad de Córdoba. Este barrio, conocido como Sabattini, se encuentra habitado mayoritariamente por migrantes peruanos (el 60\% de las personas que allî residen son de ese origen nacional) que se desempeñan principalmente en la construcción, la costura y el trabajo doméstico remunerado (Censo de Viviendas, Hogares, Población y sus Características Migratorias, 2014). En las visitas al barrio, presté especial atención a las condiciones de vida de las familias migrantes, a los roles y relaciones de género, a las formas de organización familiar y a las especificidades de las trayectorias laborales de los y las vecinas del lugar.

El análisis de las experiencias y trayectorias de los y las costureras migrantes, en tanto inserción laboral central para las familias peruanas de Sabattini, permitió de algún modo articular esas distintas dimensiones que habian organizado el trabajo de campo. En este sentido, he podido reconstruir las trayectorias laborales en costura de cuatro familias del barrio ${ }^{6}$. En particular, el trabajo etnográfico que aquí se presenta se asienta en un estudio de caso de una de esas familias ${ }^{7}$. Esta estrategia metodológica consiste en el abordaje de lo particular, priorizando el caso único, donde la efectividad de la particularización reemplaza la validez de la generalización (Stake, 1995 en Neimann y Quaranta, 2007, p. 219). Para esta investigación se privilegiaron dos

6 En el desarrollo general del trabajo de campo en Sabattini, realicé entrevistas a profundidad a migrantes peruanos, varones y mujeres, con diferentes trayectorias migratorias y laborales, resultando la costura una de las inserciones posibles para esta población.

7 La familia es concebida aquí como un espacio constituido por relaciones y jerarquías de poder y, por ende, conflictivo y heterogéneo (Ariza y Oliveira, 2002; Stolcke, 2004; Torns, 2008). 
técnicas fundamentales: la observación participante y la biografia laboral y familiar de Jorge y Jimena ${ }^{8}$.

Esta familia fue una de las primeras que conocí cuando llegué a Sabattini. Su pequeña casa se convirtió en un paso obligado en cada una de las visitas al barrio. Ambos son oriundos de Perú, nacieron en el interior del Departamento de Lima -Jorge en 1977 y Jimena en 1985- y luego migraron hacia la ciudad capital de ese país, como parte de los flujos internos en el Perú (-Jorge cuando era pequeño, junto con su familia, y Jimena en 2007). La familia está compuesta, además, por sus dos hijos nacidos en Córdoba: Renato en 2010 y Lisandro a comienzos de 2014. Además, vive con ellos Elisa, hija de la primera pareja de Jorge, quien llegó desde Lima a comienzos de 2013 con 12 años, y Daniel, el hermano menor de Jimena, que hoy tiene 22 años $^{9}$.

Jorge y Jimena arriban a Córdoba en 2009 para trabajar en un taller de costura ubicado en el centro de la ciudad, siendo contratados desde Lima por una mujer peruana, dueña de ese taller. Como se verá más adelante, ambos aprendieron el oficio de costureros como una estrategia de subsistencia, en Lima, y fue ese oficio el que le abrió a Jorge las puertas de la migración hacia Argentina ${ }^{10}$. En el año 2012 abrieron un pequeño taller domiciliario con dos máquinas de coser y luego compraron una máquina más, aunque la inestabilidad del trabajo los ha obligado a trabajar también 'fuera' de su casa, en un taller céntrico bajo la modalidad 'a destajo'11.

A partir de los aportes de la sociología laboral y de los estudios de género, este artículo busca identificar las condiciones y modalidades de

8 Los nombres de las personas mencionados a lo largo del texto han sido modificados para preservar su anonimato.

9 Daniel, a diferencia de Jorge y Jimena, se dedica a la construcción, otra de las ocupaciones típicas de los migrantes peruanos en Córdoba.

${ }^{10}$ La noción de estrategia que recorre estas páginas se asienta en la premisa según la cual los individuos y las familias poseen un margen de acción y de decisión, por más restringido que este sea (Zamorano Villarreal, 2003, p. 165).

${ }^{11}$ En el trabajo a destajo se acuerda previamente un precio por cada prenda producida: cuanto más rápido se termina con la elaboración de la prenda, más rápido se cobra el dinero. Esto deriva en jornadas laborales interminables que reproducen formas de explotación laboral. 
trabajo presentes en el universo de las tareas textiles, reconociendo que las mismas se sostienen en la segmentación étnico-nacional y de clase presentes en el mercado de trabajo en Argentina. En tanto categoría descriptiva del mundo laboral, la segmentación supone dar cuenta de una desigual distribución de puestos de trabajo entre diferentes grupos sociales, así como de los mecanismos de generización, etnización y jerarquización de la fuerza laboral. Aunque no es un fenómeno novedoso, la segmentación del mercado de trabajo se ha ido modificando en el contexto de una nueva geografia social global (Castles, 2013; Sassen, 2003). La desregulación económica de las últimas décadas bajo el auge neoliberal ha derivado en una creciente jerarquización, precarización e informalización del empleo, en especial para los migrantes, los jóvenes y las mujeres.

Desde las ciencias sociales existe una vasta producción que busca explicar este proceso y sus implicancias sociales, culturales, económicas y políticas. En el transcurso del siglo XX surgieron un conjunto de teorías orientadas a reflexionar sobre la cuestión del mercado de trabajo y su segmentación (Piore, 1979). Entre ellas, es posible mencionar la teoría del mercado de trabajo, la teoría del mercado dual o aquellas teorías de orientación marxista preocupadas por las divisiones de la clase trabajadora, con base en una lectura de los conflictos y las desigualdades que jerarquiza a la clase social por encima de las demás formas de clasificación social. Las principales críticas a estas perspectivas se fundaron en el hecho de que la segmentación laboral no se comprende teniendo en cuenta la dimensión económica como exclusiva o preeminente, sino que su compleja estructuración requiere la inclusión de múltiples dimensiones explicativas. Así pues, los feminismos han ocupado un lugar central, al visibilizar la presencia diferenciada de varones y mujeres en los ámbitos de la producción y reproducción, enfatizando los significados de esa presencia diferenciada en términos de desigualdades y de reconfiguración de lógicas de dominación patriarcales (Borderías y Carrasco, 1994; Torns, 2008).

Los estudios más recientes sobre las diversas formas de reestructuración de la fuerza de trabajo parten de reconocer que las posibilidades de que una persona obtenga empleo dependen no solo de su 
posición de clase, sino también de su género, nacionalidad, etnicidad, estatus legal, edad, ubicación y otros criterios no económicos (Browne y Misra, 2003; Castles, 2013; Fuller, 2005; Trpin y Vargas, 2005). Ahora bien, la inserción de los varones en actividades típicamente 'femeninas' ha sido un aspecto menos estudiado en el marco de las investigaciones sobre el mercado de trabajo y su segmentación.

Los varones, en un escenario de feminización de su trabajo, pueden, por un lado, experimentar las mismas condiciones laborales que las mujeres (con especial referencia a los bajos salarios, la inestabilidad y la precariedad); por el otro, pueden desplegar un conjunto de estrategias para fortalecer su identidad y minimizar las connotaciones femeninas de las actividades mediante la búsqueda de liderazgo (De la O, 2013, pp. 57-58). Esa búsqueda de liderazgo puede potenciarse cuando, en el contexto de la feminización del trabajo del varón, se comparte la misma ocupación con la pareja o esposa. Recuperando estas premisas, el artículo se organizará en torno a dos apartados: el primero reconstruirá el contexto de origen de Jorge y Jimena, cuando se inician como costureros en Perú y toman la decisión de migrar hacia Argentina. El segundo abordará las trayectorias laborales en Córdoba, prestando especial atención a las implicancias de la costura en términos de roles y relaciones de género en el ámbito laboral y familiar y también a las estrategias y resistencias frente a la 'feminización del trabajo masculino'.

\section{Migraciones internas en Perú y estrategias de subsistencia: Jorge y Jimena se convierten en costureros}

Jorge y Jimena, ambos migrantes internos, aprendieron el oficio de costureros una vez arribaron a Lima, en el marco de la escasez de oportunidades y en medio de las necesidades de subsistencia familiar. Esta actividad se presenta como una opción de acceso rápida frente a las restricciones que les impone el mercado laboral. Jorge, sobre sus inicios como costurero en Perú, recordó:

Comencé a trabajar en la costura hace como diez años, en el 2004, en Lima. Llegué ahí porque necesitaba trabajar, antes trabajaba 
de moto taxi. Por ayuda de mi hermano Ignacio, que ya tenía conocimiento del oficio es que me metí en la confección y tuve que aprender, no sabía nada. No me gustaba mucho, pero ahí había más trabajo. (Jorge, comunicación personal, Córdoba, marzo 15, 2014)

Elisa, la hija de Jorge, durante una conversación señaló: “por mí [Jorge] tuvo que trabajar en costura" (Elisa, comunicación personal, Córdoba, febrero 28, 2014). En otra oportunidad indicó que su padre:

Trabaja en costura desde hace diez años ya. Aprendió en Lima para poder mantener a la familia. Cuando era muy chiquita, sabes, mi mamá se fue, nos abandonó a mi papá y a mí. Mi papá se hizo cargo mío, luego, como a los tres años mi mamá me reclamó, pero mi papá no quería saber nada porque él me había criado. (Elisa, comunicación personal, Córdoba, abril 4, 2014)

Jimena, al explicar la inserción de Jorge en la costura, relató:

Cuando yo llegué a la costura, él ya tenía cuatro años trabajando [...] La mamá de Elisa trabajaba junto con el hermano de Jorge, pero Jorge era solo moto taxi y no le interesaba meterse en la confección. Su hermano le decía 'métete, métete', pero él no quería saber nada de eso. Cuando se separó comenzó a buscar porque el trabajo como moto taxi no le rendía. Y él tenía que dejarla a ella [a Elisa] con una señora para que la cuide y le tenía que pagar la comida y no le rendía la moto. Ahí fue cuando empezó a estudiar confección. Creo que estudió como dos meses, pero aprendió lo básico porque no le alcanzaba el dinero para poder completar [...] pero de a poco aprendió y luego me comenzó a enseñar a mí. (Jimena, comunicación personal, Córdoba, abril 4, 2014)

La incorporación en la costura de Jorge formó parte de las estrategias de supervivencia desplegadas en pos de cumplir con el mandato tradicional de varón-proveedor. La posesión de un trabajo que permita la manutención familiar es parte central de lo que se considera 'identidad masculina'. Como sugiere Rosas (2013, p. 136), el modelo de la división sexual del trabajo en las sociedades actuales, 
más allá de las formas específicas que adquiere en cada contexto socio-cultural y más allá de las dificultades para llevarlo adelante, tiene aún fuertes implicancias (materiales y simbólicas) en la vida social cotidiana. Así, independientemente de la actividad que realicen los varones, el hecho de ser proveedor es una forma de expresar su masculinidad. En el contexto de una inserción laboral temprana en sus lugares de origen, para Jorge y otros migrantes peruanos que trabajan en talleres textiles en Córdoba la costura no emerge como una primera opción laboral, sino que son las propias necesidades de reproducción social las que orientan esa inserción. Jorge y Jimena, así como otros migrantes peruanos que se dedican a esta actividad en Sabattini, conforman la primera generación de costureros en sus respectivas familias.

Según se desprende de la reconstrucción de sus trayectorias laborales, las formas de incorporación en la costura en Perú se encuentran condicionadas por roles de género delimitados que refuerzan los sentidos de lo 'masculino' y lo 'femenino':

Mi hermana [de Jimena], que ya estaba en Buenos Aires, me quería traer para acá, pero primero me fui a Lima y ahí una comadre de mi tía me llevó a Gamarra, que es como una feria, como el Once $^{12}$, pero de pura confección de ropa. En ese lugar, los costureros, los dueños de los talleres, van a buscar mujeres para que te habiliten para trabajar de ayudantes de costura. Mi tía me dice que ellos te mandan a hacer la prenda pero yo no sabía y ella me decía que cualquiera que viniera y me preguntara si era ayudante, le tenía que decir que sí, y cuando alguien preguntara por habilitadora yo tenía que levantar la mano, "porque si no levantas la mano no te llevan y te quedas sin trabajo", me dice. El primer día nadie me tomaba [...] Era una esquina donde se juntaban todas las mujeres. Y habia hombres que siempre venían a buscar mujeres no solo para que las "habiliten" sino para enamorar también ¡Son vivos! [...] Al tercer día nada, al cuarto día apareció mi angelito Jorge. El angelito Jorge con el angelito Ignacio. Ellos llegaron y se me tenía que quitar la vergüenza, al que venía yo tenía que decirles que yo si sé, porque

\footnotetext{
12 Once es un barrio de la Ciudad Autónoma de Buenos Aires.
} 
si yo le digo "yo no sé", no me van a llevar. Y vino ahí Jorge y dijo que necesitaba ayudante y yo levanté mi mano. Y ahí fue donde me preguntó: "sabes hacer esto, sabes hacer lo otro" y yo a todo le dije que sí. "Bueno, entonces vamos", me dijo. Me llevó, el Ignacio era como más serio. Jorge es, como se dice, más distendido. Me acuerdo que me dijo "compagina", que es tender la tela y colocar el molde arriba para cortarla, la espalda y el delantero separados. Él me dijo "compagina" y yo me quedé callada y él se fue a su máquina. "Ya acabaste", me decía. Hice lo mejor que pude y se lo llevé y me dice "esto no está bien, tú no sabes hacer esto", me dice y yo me quedé callada, no sabía qué decir. "No sé, pero necesito trabajar", le dije. "Bueno, yo te voy a enseñar", me dice, y me enseñó a compaginar, a cortar cuello. Allá si les daban mil remeras, las tenían que entregar en tres días sí o sí, había que hacerlo lo más rápido que se pueda y así fui aprendiendo. Todos los días trabajaba y trabajaba, mi vida era el trabajo, tanto que me olvidé de mi estómago, es que yo quería juntar plata. Mi almuerzo en Perú era un platito chiquitito con un poquito de arroz, de guiso, un vaso de chicha que estaba a 50 centavos, con tal de ahorrar y no gastar mi dinero. Pero no me daba cuenta que me estaba dañando mi estómago, empecé a tener gastritis. Y ahí me dijeron que tenía que comer bien porque si no cómo voy a trabajar. Y ahí fue cuando dejé de mezquinar a la comida. (Jimena, comunicación personal, Córdoba, abril 4, 2014)

Tanto trabajaba que me hice conocida y me llamaban de allá y de acá para trabajar. La primera amanecida me quedé con Jorge, Ignacio y dos chicos. Yo era la única mujer. Yo tenía un poco de miedo de quedarme en la noche sola con los hombres, mi tía me contaba que habia hombres que violaban a las trabajadoras [...] Yo llegué al taller con mentiras porque les dije que tenía una nena para que me contrataran y no me hicieran daño, me acuerdo que Jorge me había hecho una remerita para mi hijita (Jimena, comunicación personal, Córdoba, abril 4, 2014) ${ }^{13}$

${ }^{13}$ La categoría nativa 'amanecida' simboliza la jornada laboral sin interrupción para poder finalizar y entregar el trabajo a término. 
Gamarra es un centro comercial e industrial del rubro textil ubicado en el distrito de La Victoria, en Lima. En las últimas décadas, este espacio se ha transformado en un sector de gran dinamismo para la economía peruana, siendo sus protagonistas principales los migrantes internos que llegaron a esa ciudad en busca de oportunidades laborales (Ponce Monteza, 1994). De modo principal, Gamarra emerge como una 'solución' a la migración interna por causa de la violencia de Sendero Luminoso y de los efectos sociales de las políticas neoliberales en diferentes áreas del interior del país (Garrido Carrasco, 2008). Justamente, es hacia Gamarra donde Jorge y Jimena se dirigen, en tanto migrantes internos, para conseguir trabajo. En ese espacio, y en el marco de la costura, la reproducción de la identidad de género masculina -heterosexual- se manifiesta en la forma en que se organiza la actividad y en las relaciones de poder que la atraviesan.

Si bien varones y mujeres se dedican por igual a la confección de prendas, los modos de acercamiento a la costura son distintos: las mujeres reunidas en una esquina de Gamarra esperando la llegada de los costureros varones para que las 'elijan' como ayudantes revela la existencia de roles de género diferenciados entre quienes se desempeñan como costureros y costureras. Los temores de Jimena en torno a un trabajo con alta presencia masculina (y en posiciones de poder), las estrategias que despliega para 'protegerse' de esa situación a partir de configurarse como madre y las visiones que construye de Jorge como su 'angelito' -que remiten a la idea del varón 'protector'-, condensan esos roles diferenciados que se traducen en maneras especificas de relacionarse en el espacio laboral.

A Jorge, la costura le ha permitido cumplir con los mandatos sociales de su identidad masculina, no solo por el hecho de ser responsable de su familia y ser el principal proveedor, sino también por las jerarquías de poder que se configuran en el ámbito del taller. En este caso de estudio, la 'selección' laboral de Jimena por parte de Jorge como costurera en 2008 fue el inicio de una relación de pareja. Asimismo, el rol de Jorge como su 'maestro' lo ha configurado como el más experimentado y, por tanto, como persona 'autorizada' en la toma de decisiones (no solo vinculadas con la esfera laboral). 
La migración hacia Argentina se gestó en el marco de una de las particularidades más salientes del trabajo en costura, tanto en Perú como en Argentina, como es su inestabilidad. Así recuerda Jorge el escenario en el que tomó la decisión de migrar:

En Gamarra hay tiempo en que hay buen trabajo y tiempo en que no hay nada. Los meses en que no había trabajo, vendía remeras por los pueblos para juntar algo de dinero y mantener a la familia, pero no era mucho. Un día en Gamarra encontré un papelito que decía 'se necesitan costureros para Argentina, llamar a este número'. El papelito estaba pegado en un poste, saqué el papelito y lo guardé. Y llamé, hablé con la señora que me dio el primer trabajo [también peruana], me dijo cuánto podía ganar y me vine. (Jorge, comunicación personal, Córdoba, marzo 15, 2014)

Jimena brinda más detalles de ese momento:

Jorge vendía remeras por los pueblos también para juntar dinero, ya ahí es donde yo salí embarazada [de Renato]. Él se iba a vender las remeras, en una semana venía una sola vez nada más a la casa, a ver cómo estaba. Cuando encuentra el papelito en Gamarra sobre un trabajo en Argentina, llama a un amigo en Buenos Aires que tiene un taller de estampado y le preguntó si conocía el sitio [era en Córdoba]. Jorge estaba muy angustiado, tenía que mandarle la pensión a la nena [Elisa] que en ese momento estaba en un colegio particular, tenía que pagar mensual y el trabajo venía muy mal. Entonces, él se aventó, se iba a venir con otros tres chicos a trabajar para la señora. Yo me había quedado que él se venía para trabajar, él me decía "te voy a mandar plata" y al final aparte de los otros tres chicos que tenían que venir, la señora había contratado dos más. Pero uno de los amigos del Jorge les falló, no venía. La señora ya había comprado el boleto pero el chico, que se llamaba Diego, no venía y no iban a botar el pasaje y Jorge le dice "mi mujer sabe coser, ella puede ir también, pero ella está gestando". Y bueno, la señora me llamó y me dice "Señora, usted es la esposa de Jorge"; "sî", le digo; "Jorge me dice que me dé su documento", me dice; "para qué", le pregunto; "para que venga junto con Jorge a Argentina", me dice. Así que le di 
mi documento. Cuando vino Jorge me dice "tal fecha vamos a salir". (Jimena, comunicación personal, Córdoba, abril 4, 2014)

Ambos testimonios permiten evidenciar que la decisión de migrar surge a partir del acceso a cierta información sobre demandas laborales en Argentina. Esa información circula en un espacio dedicado a la costura en Lima, como es Gamarra, que concentra a migrantes internos y sirve como puntapié para la migración al exterior. Esto activa una red laboral entre origen y destino, encabezada por una mujer peruana que residia -y reside actualmente- en Córdoba, pero nutrida principalmente por varones costureros. La migración de Jimena no solo no estaba contemplada al comienzo del proyecto migratorio, sino que además fue una idea de Jorge luego de que uno de los costureros finalmente decidiera no migrar. A diferencia de otras dinámicas peruanas hacia Argentina, donde las mujeres han sido pioneras de la migración -en especial para incorporarse en el trabajo doméstico remunerado ${ }^{14}$-, la costura manifiesta otros modos de migrar, atravesados por condicionantes de género: cada vez más esta ocupación es un trabajo de varones migrantes que se movilizan -solos o en familia- en pos de asegurar la subsistencia familiar ${ }^{15}$.

\section{El trabajo de costura en Córdoba: presencias masculinas migrantes en trabajos feminizados}

En Argentina, la industria textil se ha caracterizado por ser un sector laboral históricamente feminizado (Barrancos, 2007; Rocchi, 2000; Ullivarri, 2009) y estructurado en torno a una división sexual del trabajo donde las mujeres se han ocupado de las tareas vinculadas con la confección de prendas, es decir, el último eslabón de la cadena productiva. Con una particularidad: desde inicios del siglo XX la

${ }^{14}$ Cuando la mujer migra como pionera, dejando en su lugar de origen al resto de su familia y se convierte en su sostén económico principal, disputa también una condición central de ciertos roles y estereotipos de género: el del varón proveedor (o principal proveedor).

${ }^{15}$ A diferencia del caso peruano, Bastia (2007) encuentra que en la migración boliviana hacia Buenos Aires son las mujeres quienes mayoritariamente se insertan en el rubro textil a partir de la segmentación del mercado laboral y su articulación con las dimensiones de género, etnicidad, clase social y condición migratoria. 
modalidad de los talleres manufactureros de delegar parte de las diversas tareas (corte, estampado, bordado, confección, terminación) al trabajo del costurero y su familia fue construyendo la institución del 'trabajo a domicilio', por subcontratación a pedido y pago a destajo (González, 2006).

Hacia finales del siglo XX y en especial a partir de la implementación de políticas neoliberales en Argentina se producen importantes transformaciones en la industria textil. Como señala Barattini (2010), la desregulación económica característica de este período derivó en la remoción de los controles legales en el empleo y en la reducción de las inspecciones de los lugares de trabajo. El escenario de la confección de prendas, continúa la autora, ha resultado propicio para que se den situaciones irregulares, tanto por la falta de regulación del Estado como por las estrategias empresariales tendientes a tercerizar determinados procesos productivos y no responsabilizarse por lo que sucede en los espacios laborales (Barattini, 2010, p. 463). Esto permitió una gran expansión en la contratación por hora o a destajo, en especial para los y las migrantes de la región sudamericana que se concentran en los trabajos manuales (Benencia, 2009, p. 50). La confección de prendas se transformó en un sector económico 'abandonado' por la gran mayoría de los varones -y mujeres- argentinos, con escasas posibilidades de movilidad social y donde prima el uso intensivo de la fuerza de trabajo, reproduciendo formas de explotación social.

En este escenario, luego de la llegada de Jorge y Jimena a Córdoba, en 2009, comienzan a trabajar y vivir en casa de la señora "que los trajo". Sin embargo, el nacimiento de su hijo Renato, las dificultades de vivir en esos espacios con bebés y los costos del alquiler los impulsaron a buscar otros lugares de residencia en la ciudad. Así, arriban primero a una casa 'apropiada' irregularmente por una persona -argentina- que alquilaba las piezas a un precio muy alto y, posteriormente, a Sabattini, un barrio ubicado en la periferia este de la ciudad de Córdoba, a partir de la 'toma' informal de los terrenos con la intención de acceder a la casa propia. En 2009 levantan -con la ayuda de una Organización no gubernamental- una pequeña casa de madera, donde residen actualmente. Una vez que dejaron de trabajar para su 
primera empleadora, comenzaron a pensar en la posibilidad de armar su propio taller de costura domiciliario. A comienzos de 2012 poseían dos máquinas de coser:

E: ¿Cuándo compraron las máquinas?

J: Más de dos años ya. Cuando se salió de la señora que nos trajo de Perú, Jorge ya se hizo conocido en la confección. Y ahí conoció un señor que se llama Lito y él le conseguía trabajo. Con él hizo trueque, Jorge trabajaba y le descontaban un porcentaje del dinero para las máquinas. Esas máquinas son compradas de ese señor, fue poco a poco, con su trabajo. (Jimena, comunicación personal, Córdoba, abril 4, 2014)

En sus relatos, Jimena confirma que fue Jorge quien resolvió dejar el primer taller, quien consiguió el trabajo posterior e incluso quien dispuso la llegada a Sabattini -aun estando ella en desacuerdo-, asumiendo un lugar central en las decisiones sobre las movilidades -laborales y espaciales- de la familia:

Una mujer conocida de Jorge nos contó de unos terrenos que se estaban tomando. Vinimos a verlos, pero a mí no me gustaron, todo esto era monte, no había nada, puro polvo. Así que le dije "vente tú solito, yo no voy". Pero finalmente acepté venir y comenzamos a construir nuestra casa. (Jimena, comunicación personal, Córdoba, septiembre 26, 2012)

En Sabattini, la costura representa una de las inserciones principales para las jóvenes familias peruanas que allí residen, bajo dos modalidades no excluyentes: el taller domiciliario y el trabajo como costureros y costureras para talleres localizados fuera del barrio ${ }^{16}$. El taller domiciliario se encuentra usualmente ubicado en el espacio destinado a la cocina. La cocina-taller de Jorge y Jimena es una pieza construida enteramente en madera (de tres por cinco metros aproximadamente), con el piso de tierra y con el techo de nylon y madera.

${ }^{16}$ De acuerdo al trabajo de campo, los y las migrantes que se dedican a la costura en Córdoba suelen trabajar para talleristas tanto peruanos como argentinos. 
Más tarde, con la llegada de Elisa, el espacio de la cocina-taller comenzó a funcionar también como su habitación.

De algún modo, la existencia del taller domiciliario disputa el patrón clásico de división sexual del trabajo que establecía que los varones salían a trabajar fuera de la casa para asegurar el ingreso monetario, mientras que las mujeres se quedaban a cargo de las tareas domésticas (Jelin, 2010). Las familias peruanas que poseen un taller domiciliario combinan los espacios dedicados a la producción y reproducción, convirtiendo al hogar, en particular al espacio reservado a la cocina, en el lugar de trabajo -permanente o temporario- de varones y mujeres (Magliano, Perissinotti y Zenklusen, 2014).

La primera vez que fui a la casa de Jorge y Jimena, se ubicaban en la cocina-taller tres mesas de trabajo con tres máquinas de coser, una en cada mesa (Registro de campo, Córdoba, marzo 10, 2012). Más adelante, en otra visita, solo quedaban dos máquinas. Fue cuando conocí a Elisa, quien había llegado recientemente desde Lima:

Entro a la cocina y Jorge me presenta a su hija, adolescente, quien estaba trabajando con él cosiendo unas carteras, "son de una Iglesia", indica. Mientras trabajaban me iban mostrando las distintas partes, "cortamos todo y pusimos los cierres y ahora estamos cosiendo las partes. Es para un congreso, tenemos que coser 800 carteras, ya la semana pasada cosí 300, esta semana otras 300 más y bueno las que quedan. No sé si llegaré para esta noche”, relataba Jorge, sin dejar de trabajar. Estaba sentado en una silla sostenida por dos ladrillos en las patas delanteras y Elisa estaba sentada en un banquito. A diferencia de la última vez que había estado en su casa, en su cocina había una máquina de coser menos. Comenta que tuvieron que empeñar una de las máquinas, "así podíamos traerla a ella de Perú, porque los pasajes están muy caros, casi 1.000 pesos, son como tres días de viaje y ya queríamos que venga, hace como un mes que está acá", dijo. Le pregunto por Jimena, y contó que "tuvo que ir a trabajar para otro lado, afuera de acá, porque para estas carteras necesitas estas máquinas, no son como las prendas, y la 
otra máquina que teníamos la tuvimos que empeñar". (Registro de campo, Córdoba, febrero 20, 2013)

A partir del momento en que armaron el taller domiciliario y debido a la inestabilidad de la costura, Jorge y Jimena han combinado el trabajo en casa (los meses en que 'hay' trabajo) con el trabajo en talleres textiles céntricos. En relación con Jimena, la inserción en la costura se ha tornado bastante irregular, como consecuencia de su rol de madre que la 'obliga' a permanecer en la casa y hacerse cargo de los menores. En las ocasiones en que ambos deben salir a trabajar, ella es quien se ocupa de las actividades vinculadas a la gestión y organización del hogar y de los niños. Así, cuando aún son lactantes, los bebés suelen acompañar a sus madres al taller, pasando gran parte del día en el espacio de trabajo ${ }^{17}$. Cuando son más grandes (pero aún no están en edad escolar), la mujer activa redes de solidaridad entre las vecinas del barrio, quienes se encargan del niño hasta que la madre regrese. Jimena, en este sentido, cuando debe trabajar fuera de su casa, lleva a Lisandro con ella y deja a Renato al cuidado de Carina o Marta, ambas vecinas, también peruanas. En relación con Jorge, en 2013 conformó un equipo de trabajo conjuntamente con su tío y su primo, también peruanos, que llegaron a Córdoba luego de que él lo hiciera. Entre los tres tratan de juntar unas 1000 piezas por encargo, trabajando 'a destajo' en un taller céntrico con el propósito de terminar cuanto antes, para así poder cobrar el dinero. Jorge suele pasar hasta tres dias sin volver a su casa a dormir -las 'amanecidas'-, revelando una modalidad laboral que, tanto en Perú como en Argentina, se caracteriza por la explotación de la fuerza de trabajo ${ }^{18}$.

Los estudios que analizan la presencia masculina en trabajos tradicionalmente asignados a las mujeres, en particular el empleo doméstico remunerado, encuentran que las representaciones sobre la

17 Esta modalidad es practicada generalmente por las mujeres-madres que se dedican a esta tarea. Analía, por ejemplo, una joven migrante peruana de 27 años que tuvo un hijo en noviembre de 2012 y que trabaja en costura, relató: "mientras coso, Francisco está acostado al lado mío en una caja con almohadones" (Analía, comunicación personal, Córdoba, marzo 10, 2013). Al ser consultada por la cantidad de horas que pasaba sentada frente a su máquina, Analía comentó que entre 12 y 14 horas diarias.

${ }_{18}$ De acuerdo a los testimonios de Jorge y Jimena y en el marco de la organización familiar, el encargado de las amanecidas en Córdoba es Jorge, no tanto porque 'aguante más', sino más bien por el rol reproductivo de Jimena, que la 'confina' durante más tiempo al ámbito del hogar. 
sexualidad masculina se plasman en la organización sexo-espacial de las labores domésticas, ubicándolos en espacios exteriores y rara vez al cuidado de menores, a diferencia de las trabajadoras, quienes son vistas como cuidadoras naturales (Durin, 2013, p. 54). Estas investigaciones evidencian que los varones pueden continuar reproduciendo prácticas y actitudes patriarcales, gozar de mejores condiciones laborales en relación con las mujeres y resistir la feminización para mantenerse en una posición dominante y monopolizar los puestos de poder (De la O, 2013; Durin, 2013).

En el estudio de caso que orienta este artículo, el trabajo de campo realizado indica que, si bien no es posible identificar una diferenciación sexo-espacial de la organización del trabajo (ambos desarrollan la actividad en los mismos lugares y espacios), así como tampoco mejores condiciones laborales para los varones en relación con las mujeres, persiste una desigual distribución de responsabilidades en las esferas productivas y reproductivas.

Según lo planteado hasta el momento, la reconstrucción de las trayectorias laborales en costura de Jorge y Jimena ofrece herramientas para reflexionar sobre dos cuestiones claves. Por un lado, el modo en que esta ocupación refuerza la clásica segmentación laboral entre migrantes y nativos y las desigualdades presentes dentro del mercado de trabajo. La diferenciación entre migrantes y nativos ha posibilitado también la constitución de ciertos nichos laborales 'protegidos' y la posibilidad de cierta movilidad social para los y las migrantes (Benencia 1997, Portes y Bach, 1985). En la costura, esta movilidad se expresa en la transición de empleados costureros a dueños de un taller (aunque pequeño, precario e informal), como el caso de Jorge y Jimena. El reconocimiento de esta movilidad no significa negar las lógicas de explotación que estructuran esta actividad, sino una de las posibles estrategias y márgenes de acción de los sujetos, en este caso migrantes, en el marco de las restricciones constitutivas del mundo laboral.

Por el otro lado, el modo en que se disputa la también clásica diferenciación de trabajos entre varones y mujeres, pues ambos (Jorge 
y Jimena) comparten la misma ocupación, realizando indistintamente la misma tarea en el mismo espacio. No obstante, esta situación no se traduce en un cuestionamiento de la identidad masculina y en transformaciones en los roles de género; al contrario, Jorge despliega estrategias de masculinización que se manifiestan en la reproducción intacta del ideal familiar del jefe varón-proveedor, en las formas en que se organiza y representa la actividad y en el sostenimiento de la división sexual del trabajo en el ámbito familiar, en donde Jimena es constituida como su 'cuidadora natural', mientras que Jorge es exonerado de las tareas reproductivas. Pero, además, las estrategias de masculinización o las resistencias a la feminización se materializan en la configuración de la costura como un trabajo transitorio para los varones, aunque en la práctica no lo sea. Así es como lo percibe Jorge.

En agosto de 2014, Jorge se compró un viejo auto y comenzó a trabajar como taxista-de manera informal- para los vecinos de Sabattini. Sin embargo, el emprendimiento duró unos pocos meses. A comienzos de octubre de ese mismo año, en una visita a su casa, ambos estaban cosiendo. Conversando con Jimena, comentó que Jorge "tenía una empresa de taxi pero ya no porque se fundió y entonces volvió a coser", a lo que agregó: "aunque no le guste, siempre vuelve a la costura." (Jimena, comunicación personal, octubre 8, 2014).

De algún modo, las trayectorias laborales de Jorge revelan la existencia de masculinidades múltiples. Por un lado, una masculinidad subalterna en torno a las inserciones en ciertas actividades, en especial en el marco de los procesos de etnización y jerarquización del mercado de trabajo, y de las implicancias materiales y simbólicas de las presencias masculinas en trabajos constituidos como 'femeninos', tanto en origen como en destino. Por el otro, una masculinidad hegemónica en torno a la reconfiguración de la identidad masculina dominante, aún en contextos de feminización del trabajo productivo, que repercute en los ámbitos laboral y familiar, los cuales continúan estando fuertemente marcados por relaciones desiguales de poder fundadas en la dimensión de género. Jorge, a través de sus prácticas, estrategias y resistencias, intenta reproducir esas desigualdades. 


\section{A modo de cierre}

Este artículo indagó sobre un tema escasamente problematizado aún dentro del campo de los estudios migratorios, como es la presencia masculina heterosexual migrante en espacios laborales reservados tradicionalmente a las mujeres. A partir de las contribuciones de la sociología laboral y de los estudios de género, reflexionó sobre el impacto de la costura, en tanto ocupación clave para los y las migrantes en Argentina, en las marcas configuradoras de las masculinidades y feminidades. El recorrido laboral de Jorge y Jimena permitió visibilizar el carácter etnizado del mercado de trabajo (en Argentina pero también en Perú), así como las estrategias que ponen en juego los y las migrantes en pos de asegurar la subsistencia y reproducción familiar.

Un amplio conjunto de los y las migrantes costureras peruanas son contratados en el país de origen, puesto que ya ejercían allí este oficio, siendo este un recurso que impulsa y facilita la migración. De manera que el análisis de las trayectorias en costura ofrece elementos para pensar la articulación entre las migraciones internas en Perú -a partir de las cuales se llega a Lima y se 'aprende' el oficio de costureroy la migración internacional hacia Argentina -a partir de ser costurero en la capital peruana-, y la conexión entre los mercados de trabajo en origen y destino, a partir de la construcción y consolidación de redes laborales étnico-nacionales.

En torno a las experiencias laborales de Jorge, tanto en Lima como en Córdoba, es posible advertir las diversas posiciones que un sujeto puede ocupar en la estructura de relaciones sociales, algunas de ellas de subordinación -en relación con la segmentación y las jerarquias presentes en el mundo del trabajo que condicionan las posibles inserciones a partir de la clase, el origen étnico-nacional, la edad y el género, entre otras formas de clasificación social-y otras de dominación -en relación con la reproducción de los modelos de masculinidad hegemónicos que constituyen roles y relaciones de género-.

El trabajo, en todas sus formas, ocupa un lugar relevante en la constitución de la identidad masculina. En el ejercicio de tareas 
definidas como femeninas y desvalorizadas socialmente, se configuran modos de expresar la masculinidad y reproducir estereotipos de género. Jorge, al ser validado como sostén principal de la familia en origen y en destino y como responsable máximo en la toma de decisiones familiares, fortalece una identidad masculina que podría verse amenazada por un empleo reservado usualmente a las mujeres en los ámbitos urbanos contemporáneos.

\section{Referencias}

Ariza, M. y Oliveira, O. (2002). Acerca de las familias y los hogares: estructura y dinámica. En C. Wainerman (Comp.). Familia, trabajo y género. Un mundo de nuevas relaciones (pp. 19-54). Buenos Aires: Unicef, Fondo de Cultura Económica.

Barattini, M. (2010). Trabajo esclavo y organización: el caso de la Unión de Trabajadores Costureros en Argentina. Estudios Demográficos y Urbanos, 25(2), 461-481.

Barrancos, D. (2007). Mujeres en la sociedad argentina. Una historia de cinco siglos. Buenos Aires: Editorial Sudamericana.

Bastia, T. (2007). From Mining to Garment Workshops: Bolivian Migrant in Buenos Aires. Journal of Ethnic and Migration Studies, 33(4), 655-669.

Benencia, R. (1997). De peones a patrones quinteros. Movilidad social de familias bolivianas en la periferia bonaerense. Estudios Migratorios Latinoamericanos, (35), 63-102.

Benencia, R. (2009). El infierno del trabajo esclavo. La contracara de las 'exitosas' economías étnicas. Avá, (15), 43-72.

Borderías, C. y Carrasco, C. (1994). Introducción. Las mujeres y el trabajo: aproximaciones históricas, sociológicas y económicas. En C. Borderías, C. Carrasco, y C. Alemany (Comps.). Las mujeres y el trabajo: rupturas conceptuales (pp. 15-110). Barcelona: Icaria. 
Browne I., y Misra, J. (2003). The Intersection of Gender and Race in the Labor Market. Annual Review of Sociology, (29), 487-513.

Castles, S. (2013). Migración, trabajo y derechos precarios: perspectiva histórica y actual. Migración y Desarrollo, 11(20), 8-42.

Censo de Viviendas, Hogares, Población y sus Características Migratorias. (2014). Informe final. Córdoba: Programa Multiculturalismo, migraciones y desigualdad en América Latina.

Cerrutti, M. (2005). La migración peruana a la Ciudad de Buenos Aires: su evolución y características. Población de Buenos Aires, 2(2), 7-28.

Defensoría del Pueblo de la Ciudad Autónoma de Buenos Aires. (2011). Las marcas de la esclavitud. Buenos Aires: Defensoría del Pueblo.

De la O, M. E. (2013). Presencias masculinas en espacios laborales femeninos. Las maquiladoras de Tezuitlán, Puebla, y Matamoros, Tamaulipas. En M. E. de la O (Coord.). Género y trabajo en las maquiladoras de México. Nuevos actores en nuevos contextos (pp. 55-92). México: CIESAS.

Durín, S. (2013). Varones en el servicio doméstico en el Área Metropolitana de Monterrey: Ideologías de género en la organización del trabajo. Trayectorias, 15(37), 53-72.

Falcón Aybar, M. del C., y Bologna, E. (2013). Migrantes antiguos y recientes: una perspectiva comparada de la migración peruana a Córdoba, Argentina. Migraciones Internacionales, 7(1), 235-266.

Foro Ciudadano de Participación por la Justicia y los Derechos Humanos. (2009). El trabajo esclavo: La nueva marca de la industria de la confección argentina. Serie de reportajes Trabajo Decente en América Latina. Lima: Red Global América Latina.

Fuller, N. (2005). Identidades en tránsito: femineidad y masculinidad en el Perú actual. En T. Valdés y X. Valdés (Eds.). Familia y vida privada. 
¿Transformaciones, tensiones, resistencias y nuevos sentidos? (pp. 107-131). Santiago de Chile: Flacso.

Garrido Carrasco, J. (2008). Modelo posfordista de Gamarra. Informe Integrar, (51), 1-20.

Goldberg, A. (2013). Un abordaje comparativo en torno a la incidencia de la tuberculosis en inmigrantes bolivianos de Buenos Aires y San Pablo. Revista Interdisciplinar da Mobilidade Humana (REMHU), 21(40), 93-106.

González, J. (2006). Trabajo servil, trabajo asalariado y desarrollo industrial. Acerca de la emergencia de formas de trabajo servil en la industria de la confección de indumentaria argentina. Inti, (46), 6-7.

Herrera, G. (2012). Género y migración internacional en la experiencia latinoamericana. De la visibilización del campo a una presencia selectiva. Politica y Sociedad, 49(1), 35-46.

Hondagneu-Sotelo, P., Estrada, E., y Ramírez, H. (2011). Más allá de la domesticidad. Un análisis de género de los trabajos de los inmigrantes en el sector informal. Papers, 96(3), 805-824.

Jelin, E. (2010). Pan y afectos. La transformación de las familias. Buenos Aires: Fondo de Cultura Económica.

Magliano, M.J., Perissinotti, V., y Zenklusen, D. (2014). Estrategias en torno a las formas de apropiación y organización del espacio en un 'barrio de migrantes' de la ciudad de Córdoba. Revista Estudios Demográficos y Urbanos, 29(3), 513-539.

Neiman, G., y Quaranta, G. (2007). Los estudios de caso en la investigación sociológica. En I. Vasilachis de Gialdino (Coord.). Estrategias de investigación cualitativa (pp. 213-238). Barcelona: Gedisa.

Piore, M. (1979). Birds of Passage: Migrant Labor in Industrial Societies. Cambridge: CUP. 
Ponce Monteza, C. (1994). Gamarra. Formación, estructura y perspectivas. Lima: Fundación Friedrich Ebert.

Portes, A., y Bach, R. (1985). Latin Journey. Cuban and Mexican Immigrants in the United States. Berkeley: University of California Press.

Rocchi, F. (2000). Concentración de capital, concentración de mujeres. Industria y trabajo femenino en Buenos Aires, 1890-1930. En F. Gil Lozano, V. Pita, y M. G. (Dirs.). Historia de las mujeres en Argentina, vol. 2 (pp. 223-243). Buenos Aires: Taurus.

Rosas, C. (2008). Varones al son de la Migración. Migración Internacional y Masculinidades de Veracruz a Chicago. México: El Colegio de México

Rosas, C. (2010). Implicaciones mutuas entre el género y la migración. Mujeres y varones peruanos arribados a Buenos Aires entre 1990 y 2003. Buenos Aires: Eudeba.

Rosas, C. (2013). Discusiones, voces y silencios en torno a las migraciones de mujeres y varones latinoamericanos. Notas para una agenda analítica y política. Anuario Americanista Europeo, (11), 127-148.

Salguero Velázquez, M. A. (2007). El significado del trabajo en las identidades masculinas. En M. L. Jiménez Guzmán, y O. Tene Guerrero (Coords.). Reflexiones sobre masculinidades y empleo (pp. 429-448). Cuernavaca: UNAM, Centro Regional de Investigaciones Interdisciplinarias.

Sassen, S. (2003). Contrageografías de la globalización. Género y ciudadanía en los circuitos transfronterizos. Madrid: Traficantes de sueños.

Stolcke, V. (2004). La mujer es puro cuento: la cultura del género. Revista Estudos Feministas, 12(2), 77-105.

Torns, T. (2008). El trabajo y el cuidado: cuestiones teórico-metodológicas desde la perspectiva de género. Empiria, Revista de Metodología de Ciencias Sociales, (15), 53-73. 
Trpin, V. y Vargas, P. (2005, agosto). Trabajadores migrantes: entre la clase y la etnicidad. Potencialidad de sus usos en la investigación socio-antropológica. Ponencia presentada en VII Congreso Nacional de Estudios del Trabajo, Asociación Argentina de Especialistas en Estudios del Trabajo, Buenos Aires.

Ullivarri, M. (2009). Conflictos laborales en la rama del vestido. La experiencia de las obreras costureras en Tucumán. 1936-1943. Zona Franca, (18), 81-98.

Vivero Vigoya, M. (2002). De quebradores y cumplidores. Sobre hombres, masculinidades y relaciones de género en Colombia. Bogotá: CES, Universidad Nacional, Fundación Ford, Profamilia Colombia.

Zamorano Villarreal, C. (2003). La aplicación de la noción de estrategia en los estudios urbanos franceses: las estrategias residenciales. Sociológica, 18(51), 165-187.

\section{Cómo citar este artículo}

Magliano, M. J. (2016). Varones peruanos en Argentina y trayectorias laborales en costura. Masculinidades, roles de género y organización del trabajo en contextos migratorios. Universitas Humanistica, 81, 331-356. http://dx.doi. org/10.11144/Javeriana.uh81.vpea 